\title{
Pediatric Multiple Sclerosis: Update in Diagnosis and Management
}

\section{Angelo Ghezzi}

Centro Studi Sclerosi Multipla, Ospedale di Gallarate, Gallarate, Italy

\section{Key Words}

Multiple sclerosis · Pediatrics · Disease-modifying therapy

\section{Epidemiology of Pediatric MS}

Although multiple sclerosis (MS) is typically considered an adult disease, it occurs also in younger patients; approximately $3-5 \%$ of the MS population is less than 16 years of age [1]. Pediatric MS differs from adult-onset MS in several important ways:

- the central nervous and immune systems of children/ adolescents are not as developed as in adults

- in children the disease is more likely to involve cerebellar and brainstem dysfunction, polysymptomatic presentation and a high relapse rate $[1,2]$.

About $30 \%$ of children with MS develop cognitive dysfunction early in the disease course; this has a negative impact on academic and social functioning [3].

Although most affected children have a disease onset during adolescence, MS can also occur before the age of 10 and is associated with a greater level of disability. In very early-onset MS, symptoms can mimic those of acute disseminated encephalomyelitis which is important for differential diagnosis. Interestingly, in younger patients (age of onset $<12$ years) the female:male ratio is close to unity

\section{KARGER}

(c) 2014 S. Karger AG, Basel

0014-3022/14/0721-0026\$39.50/0

E-Mail karger@karger.com

www.karger.com/ene
(1.2) but increases to 4.2 when age at onset is $13-15$ years [3].

The loss of locomotor function, as measured by the Expanded Disability Status Scale, takes longer from the time of first attack in pediatric- versus adult-onset MS, but pediatric patients reach disability milestones at a younger age than their adult counterparts. Comparative magnetic resonance imaging (MRI) studies have shown a higher lesion burden in children with MS compared with adults, supporting the concept that pediatric MS is more inflammatory than adult disease [4].

\section{Diagnosis of Pediatric MS}

The body of knowledge regarding immune-mediated CNS demyelinating disorders of childhood has grown substantially in latter years. In 2007, the International Pediatric Multiple Sclerosis Study Group (IPMSSG) proposed definitions and diagnostic criteria for pediatric MS, acute disseminated encephalomyelitis (ADEM), neuromyelitis optica (NMO) and clinically isolated syndrome (CIS) [1]. In tandem, the $2001 \mathrm{McD}$ onald criteria for diagnosis of MS were expanded to include children of all ages. Availability of more accurate diagnostic procedures is expected to facilitate management decisions such as use of disease-modifying therapy in children with MS [1]. 


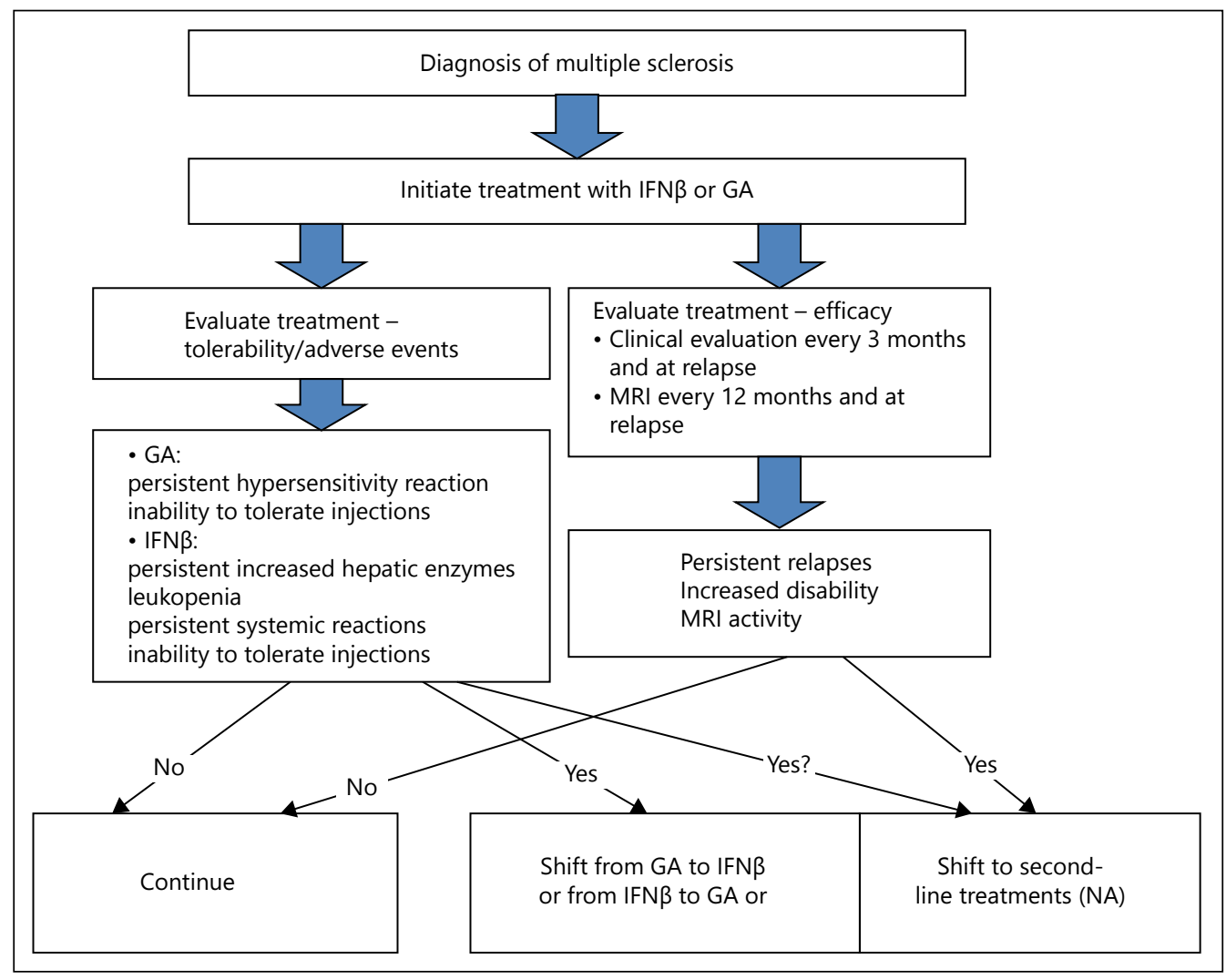

Fig. 1. Treatment algorithm for pediatric multiple sclerosis. GA = Glatiramer acetate; IFN $\beta=$ interferon-beta; $\mathrm{MRI}=$ magnetic resonance imaging $[2,4]$.

\section{Treatment of Pediatric MS}

Although no randomized controlled trials of diseasemodifying drugs are available in pediatric MS, beta interferons and glatiramer acetate are recommended based on strong evidence as first-line therapy in adult patients [4]. Several observational studies have reported on the efficacy and safety of these immunomodulating agents during short-term use in pediatric patients; beta interferons and glatiramer acetate significantly reduced the relapse rate, slowed disease progression and were generally well tolerated $[3,4]$. A treatment algorithm for pediatric MS has been developed on the basis of two consensus papers (fig. 1).

The European guidance recommends early initiation of disease-modifying therapy in children with relapsingremitting MS [3]. Similarly, the IPMSSG recommends that all pediatric patients with MS be considered for early treatment with either beta interferon or glatiramer acetate as first-line therapy to prevent the occurrence of relapses, to limit the extent of disability, and to reduce the level of CNS damage [4]. At the first demyelinating episode subjects must be monitored clinically; a second MRI is recommended 3-6 months later. If the second MRI indicates MS-defining disease activity (e.g. a new neurological episode, either new or active MRI lesions), treatment should be offered [3, 4]. However, about one-third of children with MS will not respond adequately to treatment and a second-line therapy will be required. Treatment failure is defined as the occurrence of relapses despite treatment, new MRI lesions, poor recovery after relapse and disease progression.

\section{Treatment Failure}

In cases of treatment failure or highly active disease, options include switching between first-line therapies (beta interferon and glatiramer acetate) or escalating to a second-line agent. The efficacy and overall tolerability of natalizumab have been demonstrated in a number of 
small studies but the risk of progressive multifocal leucoencephalopathy must always be considered [4]. Small studies have shown a reduction in disease activity with cyclophosphamide and mitoxantrone but their safety profiles are poor [4]. A number of other drugs such as rituximab, daclizumab and fingolimod are being evaluated, but additional studies to evaluate optimal dosing, safety and efficacy are required before these agents can be recommended as second-line therapy in pediatric MS.

\section{Conclusions}

Children with inflammatory forms of MS are at risk for serious cognitive and physical sequelae. Consensus guidelines advocate early treatment with beta interferon or glatiramer acetate. For children who experience disease relapses, second-line therapies such as natalizumab may need to be explored but caution is advised. Robust clinical studies in pediatric MS patients, evaluating current and emerging therapies, are essential to identify optimal therapeutic options for this patient population, particularly in the second-line setting.

\section{Disclosures/Conflict of interest}

AG has received honoraria from Almirall SA, Biogen, Genzyme, Merck-Serono and Novartis.

Writing assistance was provided by Content Ed Net (Madrid, Spain), with funding from Laboratorios Almirall, SA (Barcelona, Spain).

\section{References}

1 Krupp LB, Tardieu M, Amato MP, Banwell B, Chitnis T, Dale RC, Ghezzi A, Hintzen R, Kornberg A, Pohl D, Rostasy K, Tenembaum S, Wassmer E; International Pediatric Multiple Sclerosis Study Group: International Pediatric Multiple Sclerosis Study Group criteria for pediatric multiple sclerosis and immune-mediated central nervous system demyelinating disorders: revisions to the 2007 definitions. Mult Scler 2013;19:1261-1267.
Ghezzi A: Clinical characteristics of multiple sclerosis with early onset. Neurol Sci 2004; 25(suppl 4):S336-S339.

3 Ghezzi A, Banwell B, Boyko A, Amato MP, Anlar B, Blinkenberg M, Boon M, Filippi M, Jozwiak S, Ketelslegers I, Kornek B, Lim M, Lindstrom E, Nadj C, Neuteboom R, Rocca MA, Rostasy K, Tardieu M, Wassmer E, Catsman-Berrevoets C, Hintzen R: The management of multiple sclerosis in children: a European view. Mult Scler 2010;16:12581267.
4 Chitnis T, Tenembaum S, Banwell B, Krupp L, Pohl D, Rostasy K, Yeh EA, Bykova O, Wassmer E, Tardieu M, Kornberg A, Ghezzi A; International Pediatric Multiple Sclerosis Study Group: Consensus statement: evaluation of new and existing therapeutics for pediatric multiple sclerosis. Mult Scler 2012;18: 116-127. 